\title{
Adipose-Lung Cell Crosstalk in the Obesity-ARDS Paradox
}

Ana Fernandez-Bustamante and John E Repine*

Department of Anesthesiology \& Webb-Waring Center, University of Colorado SOM, USA

\begin{abstract}
Obesity is an increasingly frequent condition associated with increased adipose, systemic and pulmonary inflammation. There is an emerging and unexpected finding that obese individuals may not be at a greater risk for ARDS and, indeed, may even be partially protected against ARDS. This finding is known as the Obesity-ARDS Paradox. In this review we discuss the observations regarding this intriguing phenomenon and begin to elaborate on the theoretical rationale that obesity-triggered low-grade inflammatory processes may constitute pre-conditioning insults or trigger anti-inflammatory adaptive mechanisms that confer protection against ARDS.
\end{abstract}

\section{The Obesity-ARDS Paradox}

Obesity is an increasing global epidemic that increases cardiovascular abnormalities, diabetes, sleep apnea and mortality [13]. The Acute Respiratory Distress Syndrome (ARDS) is a highly fatal respiratory failure disorder [4,5]. Because both obesity and ARDS are characterized by increased inflammation and oxidative stress [612], obesity might reasonably be considered a risk factor for ARDS. However, the opposite seems to be the case. Although obese patients manifest a greater incidence of certain pro-inflammatory respiratory diseases, such as sleep apnea and asthma $[13,14]$, they actually have a lower than expected incidence and/or severity of ARDS in a number of studies (Table 1) [15-21]. This unexplained finding is termed the "Obesity-ARDS Paradox." Some of these studies are retrospective in nature or do not allow the investigation of the concept that has been termed "Metabolically Healthy Obesity" (MHO) [22,23] terminology that refers to obese individuals with no associated metabolic comorbidities (insulin resistance, atherosclerosis, liver dysfunction). Interestingly, this $\mathrm{MHO}$ concept has been linked to lower adiposerelated inflammatory profiles and a lower mortality risk compared to individuals with metabolically unhealthy obesity [24]. How obesity may affect systemic and even pulmonary inflammatory responses is the key focus of this review. The differences in the metabolic and inflammatory backgrounds of patients in studies that do not fully support the Obesity ARDS Paradox phenomenon may explain their different conclusions. However, the finding of multiple studies showing a lower-than-expected mortality (including lower mortality $[15,19,20]$ or similar mortality $[17,18,21]$ than normal weight patients) in obese individuals after ARDS is provocative. Elucidating the causes of this observation should increase understanding of the causes of ARDS and, perhaps, lead to new and needed therapeutic approaches.

\section{Pre-Conditioning as a Mechanism Contributing to the Obesity-ARDS Paradox}

The underlying mechanism responsible for the Obesity-ARDS Paradox is unknown. Confronted with trying to elucidate a reason, we hypothesized earlier [25] that obesity-induces a low-grade inflammation that generates a process that subsequently protects the lung against later insults. We termed this protective response the "pre-conditioning cloud" because the mechanism responsible for protection is nebulous at this time and likely to be multi-factorial in nature. However, the possibility of a pre-conditioning protective response is not new. The pre-conditioning or "tolerance" concept has been appreciated for many years. In its simplest presentation, pre-conditioning implies that a minor "first hit"---a relatively small inflammatory and/or oxidative insult that does not generate overwhelming damage---somehow creates a beneficial reaction that reduces the detrimental inflammation and/or oxidative stress a more aggressive and damaging "second hit". Double (or multiple) hits are common in clinical settings; for example, when a patient sustains trauma ("first hit") and then becomes infected ("second hit"). This double hit injury in which an initial insult (for example sepsis or trauma) primes and worsens the injury caused by a second insult (pneumonia or sepsis), rather than a first hit reducing the damage caused by a second hit, has also been observed in animal models and often used to create a greater lung injury $[26,27]$.

Notwithstanding the detrimental consequences of a double hit injury, many observations show that a prior insult, if occurring under the right conditions with the right timing, can provide protection against a second insult in animals [28-30] and humans [31,32]. Several observations in animals are relevant. With respect to lung injury, good examples exist in studies of the acute edematous lung injury ("ARDS") that develops in rats exposed continuously to hyperoxia (100\% oxygen). Pre-treating rats with endotoxin, TNFa and IL-1, or $85 \%$ oxygen increases the survival of rats in hyperoxia [28-30]. The underlying mechanism is not clear but a common feature of these initial insults is that they each produce an inflammatory and oxidative response of apparently manageable proportions. A second feature of this protective response appears to be that time is required between the first and second insult for optimal protection to be achieved. In addition, a "cross-tolerance" can occur whereby pre-treating with one insult (e.g. ozone) will diminish the injury seen by different insult (e.g. hyperoxia) [33]. The protective response is not simply related to increases in antioxidants, which do not increase following every insult.

\section{Theoretical Pre-Conditioning Mechanisms Contribut- ing to the Obesity ARDS Paradox}

Several mechanisms have been proposed as responsible for preconditioning development, including an increase of TNFa and other cytokines [29,34,35], and of heme oxygenase-1 (HO-1) [36], among others [37-39] . Interestingly, obesity raises the adipose and plasma levels of TNF $\alpha$ and other cytokines [40] and of HO-1 [41,42]. For example, one could hypothesize that the adipose-triggered first hit inflammatory mediators (e.g. adipose-released TNFa or other cytokines) locally

*Corresponding author: John E Repine, MD, Director, Webb-Waring Center, University of Colorado SOM, 12850 E Montview Blvd, Webb-Waring Center, V20 MS 322, Aurora, CO, 80045, Tel: 303-724-4783; E-mail: John.Repine@ucdenver.edu

Received March 16, 2013; Accepted April 17, 2013; Published April 19, 2013

Citation: Bustamante AF, Repine JE (2013) Adipose-Lung Cell Crosstalk in the Obesity-ARDS Paradox. J Pulmon Resp Med 3: 144. doi:10.4172/2161-105X 1000144

Copyright: $(2013$ Bustamante AF, et al. This is an open-access article distributed under the terms of the Creative Commons Attribution License, which permits unrestricted use, distribution, and reproduction in any medium, provided the original author and source are credited. 


\begin{tabular}{|c|c|c|}
\hline Reference & Study Description & Findings/Comments \\
\hline \multicolumn{3}{|c|}{ Obesity is associated with decreased incidence and/or severity of ARDS } \\
\hline O’Brien, 2006 [20] & $\begin{array}{l}\text { Retrospective multi-center study comparing BMI with in- } \\
\text { hospital mortality in mechanically ventilated adult patients } \\
\text { with ALI/ARDS ( } n=1,488 \text { patients between } 1995 \text { and } \\
\text { 2001). }\end{array}$ & 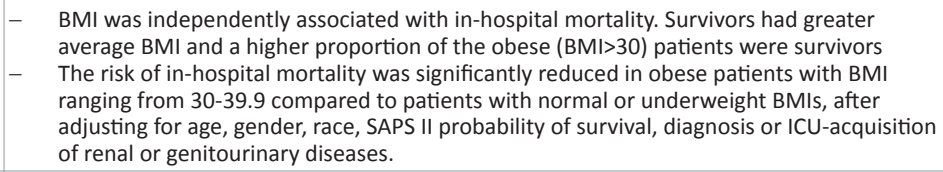 \\
\hline Morris, 2007 [19] & $\begin{array}{l}\text { Prospective multi-center observational study analyzing the } \\
\text { relationship between BMI at hospital admission and clinical } \\
\text { outcomes in ALI patients ( } n=825 \text { patients, 1999-2000). }\end{array}$ & 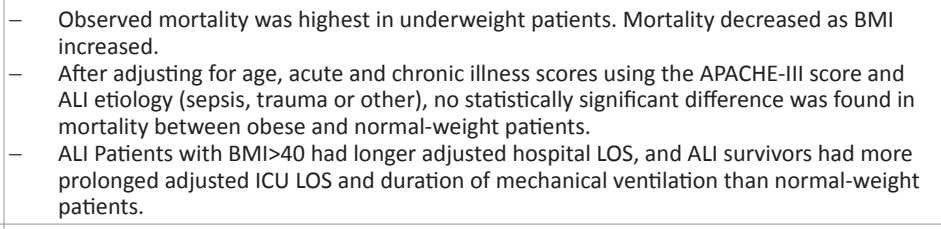 \\
\hline Memtsoudis, 2012 [15] & $\begin{array}{l}\text { Database study using the Nationwide Inpatient Sample } \\
\text { (NIS) developed by the Agency for Healthcare Research } \\
\text { and Quality (AHRQ) which compared the mortality in } \\
\text { obese vs. non-obese patients with diagnoses of RI/ARDS } \\
\text { after surgery ( } n=9,149,030 \text { surgical admissions between } \\
1998 \text { and 2007). }\end{array}$ & 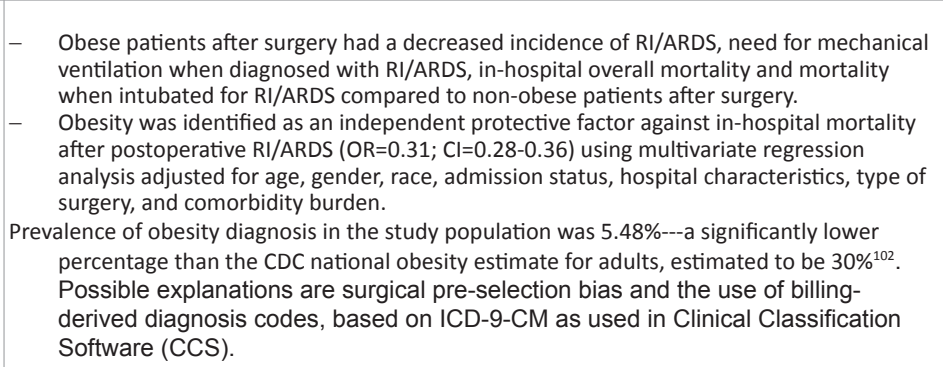 \\
\hline \multicolumn{3}{|c|}{ Obesity does not increase ARDS severity } \\
\hline O’Brien, 2004 [21] & $\begin{array}{l}\text { Retrospective multi-center study comparing BMI with in- } \\
\text { hospital mortality in mechanically ventilated adult patients } \\
\text { with ALI/ARDS ( } n=807) \text {. }\end{array}$ & $\begin{array}{l}\text { - Ventilator-free days and mortality were similar to those in normal-weight patients. } \\
\text { - } \quad \text { Underweight }(\mathrm{BMI}<18.5) \text { and extremely obese patients (weight }(\mathrm{kg}) \text {-to-height }(\mathrm{cm}) \geq 1.0) \\
\text { were excluded from the analysis. }\end{array}$ \\
\hline Gong, 2010 [17] & $\begin{array}{l}\text { Prospective multi-center study analyzing BMI as risk factor } \\
\text { for ARDS development and severity in patients at risk for } \\
\text { ARDS at ICU admission ( } n=1,795,1999-2007) \text {. }\end{array}$ & $\begin{array}{l}\text { - } \\
\text { - } \\
\text { Patients who developed ARDS had greater average BMI, and BMI was positively } \\
\text { correlated with ARDS development. ARDS development in obese patients occurred later } \\
\text { in the ICU stay than in normal-weight patients. Authors suggested that the observed } \\
\text { ventilatory settings might have played a role in the delayed ARDS development in obese } \\
\text { patients. } \\
\text { Obesity was not associated with an increased ICU-mortality or with an increased 60-day } \\
\text { mortality. Survivors had greater average BMI than non-survivors. }\end{array}$ \\
\hline Anzueto, 2011 [18] & $\begin{array}{l}\text { Secondary analysis of prospective observational multi- } \\
\text { center study cohort of mechanically ventilated ICU patients } \\
\text { designed to analyze the effect of BMI on outcomes of } \\
\text { mechanical ventilation, including ARDS development } \\
\text { ( } n=4,698, \text { April 2004). }\end{array}$ & 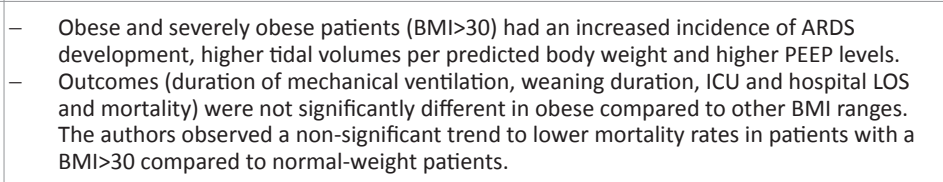 \\
\hline \multicolumn{3}{|c|}{ Obesity is associated with lower inflammatory biomarkers during ARDS } \\
\hline Stapleton, 2010 [16] & $\begin{array}{l}\text { Retrospective analysis of the effect of BMI on plasma } \\
\text { biomarkers and outcomes in ARDS patients evaluated in } \\
\text { previous NHLBI ARDSNet trials } \\
(n=1,409) \text {. }\end{array}$ & $\begin{array}{l}\text { - } \quad \text { BMI was not associated with increased mortality. } \\
\text { - } \quad \text { After adjusting for gender, APACHE III score, coexisting diabetes, and ALI risk factors, } \\
\text { obese patients (BMI>30) had lower plasma IL-6, IL-8, and SP-D levels and higher plasma } \\
\text { protein C and vWF levels, compared to normal-weight patients. }\end{array}$ \\
\hline
\end{tabular}

(ALI=Acute Lung Injury; ARDS=Acute Respiratory Distress Syndrome; ARDSNet= Acute Respiratory Distress Syndrome Network; BMI=Body Mass Index; ICU=Intensive Care Unit; LOS=Length of Stay; NHLBI=National Heart Lung and Blood Institute; RI=Respiratory Insufficiency; SAPS II=Simplified Acute Physiology Score II; SP$\mathrm{D}=$ Surfactant Protein $\mathrm{D}$; vWF=von Willebrand Factor)

Table 1: Studies related to the Obesity-ARDS Paradox concept.

the physiological negative control responses. The possibilities include inducing early p38-MAPK activation, degradating I $\kappa \mathrm{B} \alpha$ which leads to activation of $\mathrm{NF \kappa B}$, and inducing a late up-regulation of $\mathrm{IB} \beta$ that prevents a prolonged TNF $\alpha$ synthesis [34]. The TNF $\alpha$ preconditioning reaches the systemic circulation in ischemia-reperfusion models [34] and therefore could contribute to anti-inflammatory protection against second hits not only locally but also at a distance (as seen in the remote ischemic preconditioning) [37].

One alternate explanation that may be possible but is not as well supported at this time, for example, is that the initial obesityinduced insult (first hit) could then directly reduce the power of the second inflammation and/or oxidative stress insult: The distinction being that the inflammatory and/or oxidative stress response is intrinsically decreased rather than impacted by competing protective responses.

\section{Obesity Related Processes that Might Trigger the Pre- Conditioning Mechanisms}

The unexpected finding that obesity creates an intrinsic resistance to ARDS is particularly intriguing because obesity actually worsens the outcome of other inflammatory related abnormalities such as hypertension, diabetes and sleep apnea [43-46]. One aspect that might underlie this difference is that ARDS is an acute disorder while hypertension, diabetes and sleep apnea are chronic conditions. However, the intensity and nature of the pre-conditioning insult, more than the timing, are likely critical in determining any increases in 
protection against injury achieved through this mechanism. Obviously, no matter what level of protection might be generated by the increased inflammation, oxidative stress and/or other processes occurring in obesity, the presence of too many and/or potent simultaneous proinflammatory/oxidative stress "hits" might overwhelm any protective adaptation conferred by obesity.

Until recently, adipose tissue-triggered inflammation was not considered to be especially influential systemically. However, it is increasingly clear that subtle changes in adipose tissue during obesity development constitute mechanisms that may have far reaching effects contributing to abnormalities in systemic and pulmonary circulations. For example, recent findings suggest that obesity suppresses adipose genes encoding proteins involved in transcription regulation, cell adhesion, and immune regulation. These genetic changes occur not only in adipocytes but also in macrophages [47]. Interestingly, this pattern of gene repression resembles the same responses that occur during endotoxemia in healthy humans, suggesting a pattern for an endogenous reactive protection reaction. In addition, there is a growing awareness of the responsiveness of the adipose tissue to ongoing systemic insults. During critical illness and, again for unknown reasons, adipose tissue macrophages shift from pro-inflammatory M1 to alternative or anti-inflammatory M2 phenotypes [48]. These examples suggest that a relatively fluid bidirectional cell-to-cell crosstalk exists between the adipose tissue and the systemic circulation. This interaction might be especially meaningful with respect to the circulation and function of the lung. The following proposed mechanisms have not been proven in the adipose-lung crosstalk. However, different findings suggest their potential role in either producing a direct immune-modulating effect in the lung and/or initiating an indirect response by triggering adaptive responses (as in the pre-conditioning models). Further research is needed to better understand the adipose-lung cell crosstalk pathways. This information may provide insight into the potential mechanisms contributing to the obesity generated pre-conditioning responses that may account for the Obesity-ARDS Paradox.

\section{Pre-Conditioning Humoral Adipose-Lung Crosstalk Candidate Molecules}

\section{Adipocytokines}

Hypertrophied adipocytes that characterize obesity secrete increased amounts of pro-inflammatory cytokines and chemokines, including leptin, TNFa, IL-6, Monocyte Chemoattractant Protein-1 (MCP-1) and osteopontin compared to adipocytes from non-obese subjects [49-51]. While TNFa, IL-6 and MCP-1 are ubiquitously produced, leptin is primarily secreted by white adipose tissue and leptin plasma levels are proportional to adiposity [52]. Interestingly, several findings suggest a role of leptin on lung inflammation. Leptin is increased in the plasma and bronchoalveolar lavage fluid of obese patients compared to healthy controls [52,53], but also in the BAL of non-obese ARDS patients compared to ventilated non-ARDS controls [54]. Several leptin receptor isoforms exist in different pulmonary cell types, including bronchial, alveolar epithelial and alveolar macrophages [55]. It is well known that leptin promotes the release of Th1-related cytokines [55], but recent findings suggest that leptin is also an immunomodulator in the lung with a role in efficient defense against infection [56,57] and exposure to smoke [58] in mice. Treating murine alveolar or peritoneal macrophages with leptin in vitro increases phospholipase A2 activity that in turn increases synthesis of leukotriene B4 (LTB4) and cysteinyl leukotrienes (LTC4, LTD4, LTE4, LTF4) [59]. Therefore, the adipose-originated leptin appears to have the capacity to convert distant alveolar macrophages towards pro-inflammatory phenotypes and is a direct adipose-lung crosstalk mediator. This obesity-triggered leptin-mediated inflammation modulates the pulmonary inflammatory background and may contribute to more efficient responses against further insults (being infection, smoke or others) as suggested earlier by other pre-conditioning methods. Leptin-related adaptations might stimulate protective responses that attempt diminishing inflammation and/or oxidative stress against further insults in the lung. These possible connections make leptin a reasonable candidate for involvement in the Obesity-ARDS Paradox, although the specific mechanisms remain to be elaborated.

Adiponectin, an anti-inflammatory adipocytokine, decreases during obesity development [60]. Adiponectin receptors also exist in the lung and their function is best linked to protection against allergenicrelated inflammatory responses [55,61]. Adiponectin-deficient mice show emphysematous-looking lungs and alveolar macrophages that produce increased TNFa and matrix metalloproteinase-12 (MMP2) [62]. Interestingly serum, more than pulmonary, adiponectin levels may modulate Lipopolysaccharide (LPS)-induced ARDS [63] In a study by Konter et al. [63], adding adiponectin to pulmonary endothelial cells in vitro inhibited their LPS-induced IL-6 production, and ARDS was increased in adiponectin-deficient mice. The authors suggest that the obesity-associated serum adiponectin deficiency may explain the increased pulmonary vascular inflammatory responses and an increased risk to ARDS. However, the Obesity-ARDS Paradox is a clinical observation [15-21], and one could also hypothesize that the greater pulmonary vascular inflammation related to the decreased adiponectin during obesity leads to earlier or more efficient defensive responses against a later insult. Furthermore, recent findings are highlighting the differences in genetic inflammatory behavior between mice and humans [64] counsel caution interpreting any animal-based studies reflecting inflammation until confirmed in humans.

\section{Heme oxygenase-1}

Heme-oxygenase-1 (HO-1) is a heme-catalyzing enzyme that is elevated in the lungs of ARDS patients [65]. HO-1 induction has antiinflammatory and antioxidant properties in a variety of inflammatory diseases including ARDS [66-68] but also obesity [69,70]. Increased monocyte/macrophage $\mathrm{HO}-1$ is also associated with increased anti-inflammatory or M2 activation phenotypes (through arginase activity), greater phagocytic capacity, accelerated IL-10 production, and decreased macrophage inhibitory factor (MIF), TLR4, and iNOS activity via p38 MAPK [66,71-73]. For unknown reasons, HO-1 is increased in the adipose macrophages of obese humans compared to lean subjects [41]. Thus, obesity-initiated macrophage HO-1 increases could possibly represent a natural defensive attempt for controlling ongoing inflammation produced as a consequence of obesity. It is unclear if the obesity-induced increase in macrophage HO-1 expression concomitantly occurs in the alveolar macrophages, but this adaptation could constitute the vehicle for producing a protective pre-conditioning in the lung by attenuating inflammatory responses after later insults. The theoretical obesity-triggered HO-1 increase in the lung could contribute to the Obesity-ARDS Paradox by downregulating neutrophil migration [74] and/or by down-regulating Iא-B and IFN- $\beta[75,76]$. The pro-inflammatory TNF- $\alpha$, one of first cytokines in the NF- $\kappa B$ cascade, is associated with alveolar neutrophil recruitment, increased insulin resistance, type 2 diabetes and obesity $[77,78]$. Therefore, increases in HO-1 may be an endogenous negative feedback process that can modulate the obesity-induced NF- $\kappa$ B cascade and perhaps lead to attenuation of neutrophil recruitment, and ARDS development, following later insults. 


\section{Peroxisome-Proliferator (PPAR- $\gamma)$}

The peroxisomal proliferator-activated receptor- $\gamma(\operatorname{PPAR}-\gamma)$ is a nuclear ligand-activated transcription factor of the nuclear receptor superfamily. PPAR- $\gamma$ is endogenously activated by several unsaturated fatty acids [79], and is most prevalent in intestine and adipose tissue but also found in vascular endothelium and macrophages [80]. PPAR- $\gamma$ has appreciable metabolic and pulmonary effects. PPAR- $\gamma$ activation attenuates adipose inflammation and insulin resistance [81,82]. PPAR- $\gamma$ stabilizes HO-1 mRNA [76], decreases IFN- $\beta$ expression [76], and promotes $\mathrm{M} 2$ phenotype polarization in monocytes and macrophages [81]. In the lung, PPAR- $\gamma$ activation decreases TNF- $\alpha$, reduces oxidative stress and protects alveolar type II epithelial cells from LPS-induced apoptosis in vitro $[83,84]$.

PPAR- $\gamma$ is down-regulated by the obesity-mediated increases in leptin [85] a finding that may be responsible for the increased pro-inflammatory and fibroproliferative changes in lungs of leptinresistant mice and human fibroblasts ${ }^{54}$. This phenomenon known as "leptin resistance" is a desensitization to circulating leptin that also occurs in obese patients [86,87]. Although the mechanism is unclear, both the leptin-resistant PPAR- $\gamma$ increase, and the leptin-induced pro-inflammatory "first hit", could theoretically participate in lung preconditioning and the Obesity-ARDS Paradox. The relationship of PPAR- to this phenomenon warrants further investigation.

\section{Cellular adipose-lung crosstalk}

Because of their capacity to quickly respond to broad stimuli, cells of the immune system travel through the circulation and communicate among themselves and other cell types. Consequently, inflammatory cells related to obesity are likely participants in any mechanism(s) involved in the Obesity ARDS Paradox. Nonetheless, despite our focus on inflammatory cells, other intermediary cells, such endothelial or epithelial cells, may likely contribute to the preconditioning process,

Neutrophils: Several findings suggest that obesity affects neutrophil count and function. First, neutrophil counts are increased in the blood of obese humans $[88,89]$; neutrophil counts also correlate with body mass index and waist circumference in obese female adolescents [88]. Despite their increased number, little is known about the functional activities of the neutrophils of obese patients. However, neutrophil recruitment is decreased in obese compared to lean mice in a murine LPS-induced ARDS model, In addition, neutrophils from uninjured leptin-resistance and diet-induced obese mice show a decreased chemoattractant migration to chemokine $\mathrm{KC}$, and a decrease in neutrophil CXCR2 expression was suggested as an involved mechanism [90]. In this study by Kordonowy et al. [90], the neutrophil surface expression of chemokine receptor CXCR2 (also known as IL-8 receptor $\beta$ ) was significantly reduced in obese compared to lean mice. Therefore, although not confirmed in humans, it is possible that an obesity-related neutrophil impairment contributes to the unexpected lower incidence of ARDS development in obese humans.

Monocytes/macrophages: During the development of obesity, there is an increase in migration and infiltration activities of blood circulating monocytes, which are attracted by adipose tissue products: MCP-1, CXCL14, osteopontin, Angptl2, etc [91]. Macrophage infiltration in adipose tissue occurs before the development of insulin resistance in animal models [82,92]. Monocytes/macrophages are very heterogeneous in their activation profiles and function, primarily reflecting their local metabolic and immune microenvironment $[8,93,94]$. Macrophage activation phenotypes can modulate the inflammatory cascade by releasing different substances with a more pro-inflammatory profile (i.e. TNFa, IL-1 $\beta$, IL-6) in $\mathrm{M} 1$ phenotypes, vs. a M2 profile (i.e. IL-4, IL-10) with anti-inflammatory, immunomodulatory or pro-healing properties. Obesity induces a switch in adipose tissue macrophages from M2 to M1 phenotypes [8]. Whether from adipocytes or adipose macrophages, TNF $\alpha$ and other pro-inflammatory mediators (as discussed earlier) keep re-emerging as possible mediators of an obesity-related pre-conditioning response. Nevertheless, it is not known if or how macrophage changes in the adipose tissue affect the remote lung, but macrophage-derived TNFa locally induces lipolysis in adipocytes via their TNFa receptor, releasing saturated fatty acids that in turn further enhance inflammatory changes via the TLR4 receptor [95]. Because new macrophage phenotypes are still being described [94], their functions and secreting profiles could also have roles in the process underlying the Obesity-ARDS Paradox.

Lymphocytes: Lymphocyte subpopulations have recently attracted attention for their potential role in obesity. Lymphocytes could possibly be involved in the crosstalk between the adipose tissue and the lung during obesity development. Blood T lymphocytes increase with obesity $[88,96]$, although the mechanisms responsible for these increases are not well understood. In adipose tissue, CD8+ effector T lymphocytes play a critical role in initiating and maintaining adipose-related inflammation. Nishimura et al. [97] recently showed that CD8+ T cells increase in the adipose tissue in diet-induced murine obesity and in human obesity. In this key study Nishimura et al. [97] also showed that CD8+ T cell infiltration precedes macrophage infiltration and enhances M1 macrophage phenotypes and adipose inflammation. Macrophage chemoattractant protein (MCP)-1 is a key messenger in this CD8+ T-mediated macrophage recruitment [97]. Paradoxically, a recent flow cytometry study reported normal levels of CD8+ T lymphocytes in the peripheral blood, but increased CD4+ T cells, in morbidly obese patients compared to lean patients [98]. The increased CD4+ cells had a more Treg- and Th2-phenotype, which suggests a shift towards more anti-inflammatory profiles [98]. Whether this anti-inflammatory shift exists in all degrees of obesity needs to be confirmed, but it strongly suggests a complex still under-explored crosstalk of different $\mathrm{T}$ cell subpopulations infiltrating the adipose tissue at different time points during obesity. The long-distant effect of lymphocyte subpopulations in the systemic circulation and the lung is still unknown and there is insufficient evidence regarding the involvement of T-lymphocytes in ARDS.

\section{Conclusions}

The surprising observation and well-named Obesity-ARDS Paradox potentially offers important insights into the causes, treatment and prevention of ARDS. This provocative observation is further underscored by another unanticipated observation showing that patients with diabetes also have a decreased incidence of ARDS [99,100]. Both of these clinical findings were likely unexpected at the time, although it had been shown previously that higher glucose can impair neutrophil bactericidal function and this may have impaired their ability to cause lung damage as well [101]. Whether the mechanism(s) are triggered by adiposity itself or adipose-related hyperglycemia, the reality is that the human body appears to have the capacity to develop its own endogenous ways of protecting itself against a highly lethal insult like ARDS. These protective responses are impressive as well as underexplored, and likely hold meaningful clues for providing an effective treatment or prevention strategy for ARDS.

\section{References}

1. Alberti KG, Zimmet P, Shaw J; IDF Epidemiology Task Force Consensus Group (2005) The metabolic syndrome--a new worldwide definition. Lancet 366: 10591062. 
2. Dietz WH (2011) Reversing the tide of obesity. Lancet 378: 744-746.

3. Flegal KM, Carroll MD, Ogden CL, Curtin LR (2010) Prevalence and trends in obesity among US adults, 1999-2008. JAMA 303: 235-241.

4. Phua J, Badia JR, Adhikari NK, Friedrich JO, Fowler RA, et al. (2009) Has mortality from acute respiratory distress syndrome decreased over time?: A systematic review. Am J Respir Crit Care Med 179: 220-227.

5. Villar J, Blanco J, Añón JM, Santos-Bouza A, Blanch L, et al. (2011) The ALIEN study: incidence and outcome of acute respiratory distress syndrome in the era of lung protective ventilation. Intensive Care Med 37: 1932-1941.

6. Lumeng CN, Bodzin JL, Saltiel AR (2007) Obesity induces a phenotypic switch in adipose tissue macrophage polarization. J Clin Invest 117: 175-184.

7. Fujisaka S, Usui I, Bukhari A, Ikutani M, Oya T, et al. (2009) Regulatory mechanisms for adipose tissue M1 and M2 macrophages in diet-induced obese mice. Diabetes 58: 2574-2582.

8. Morris DL, Singer K, Lumeng CN (2011) Adipose tissue macrophages: phenotypic plasticity and diversity in lean and obese states. Curr Opin Clin Nutr Metab Care 14: 341-346

9. Bunnell E, Pacht ER (1993) Oxidized glutathione is increased in the alveolar fluid of patients with the adult respiratory distress syndrome. Am Rev Respir Dis 148: $1174-1178$.

10. Meduri GU, Kohler G, Headley S, Tolley E, Stentz F, et al. (1995) Inflammatory cytokines in the BAL of patients with ARDS. Persistent elevation over time predicts poor outcome. Chest 108: 1303-1314

11. Pugin J, Ricou B, Steinberg KP, Suter PM, Martin TR (1996) Proinflammatory activity in bronchoalveolar lavage fluids from patients with ARDS, a prominent role for interleukin-1. Am J Respir Crit Care Med 153: 1850-1856.

12. Wurfel MM (2007) Microarray-based analysis of ventilator-induced lung injury Proc Am Thorac Soc 4: 77-84.

13. Punjabi NM (2008) The epidemiology of adult obstructive sleep apnea. Proc Am Thorac Soc 5: 136-143.

14. Lugogo NL, Kraft M, Dixon AE (2010) Does obesity produce a distinct asthma phenotype? J Appl Physiol 108: 729-734

15. Memtsoudis SG, Bombardieri AM, Ma Y, Walz JM, Chiu YL, et al. (2012) Mortality of patients with respiratory insufficiency and adult respiratory distress syndrome after surgery: the obesity paradox. J Intensive Care Med 27: 306311.

16. Stapleton RD, Dixon AE, Parsons PE, Ware LB, Suratt BT; NHLBI Acute Respiratory Distress Syndrome Network (2010) The association between BMI and plasma cytokine levels in patients with acute lung injury. Chest 138: 568577.

17. Gong MN, Bajwa EK, Thompson BT, Christiani DC (2010) Body mass index is associated with the development of acute respiratory distress syndrome. Thorax 65: 44-50.

18. Anzueto A, Frutos-Vivar F, Esteban A, Bensalami N, Marks D, et al. (2011) Influence of body mass index on outcome of the mechanically ventilated patients. Thorax 66: 66-73.

19. Morris AE, Stapleton RD, Rubenfeld GD, Hudson LD, Caldwell E, et al. (2007) The association between body mass index and clinical outcomes in acute lung injury. Chest 131: 342-348.

20. O’Brien JM Jr, Phillips GS, Ali NA, Lucarelli M, Marsh CB, et al. (2006) Body mass index is independently associated with hospital mortality in mechanically ventilated adults with acute lung injury. Crit Care Med 34: 738-744.

21. O'Brien JM Jr, Welsh CH, Fish RH, Ancukiewicz M, Kramer AM; National Heart, et al. (2004) Excess body weight is not independently associated with outcome in mechanically ventilated patients with acute lung injury. Ann Intern Med 140 338-345.

22. Blüher M (2010) The distinction of metabolically 'healthy' from 'unhealthy' obese individuals. Curr Opin Lipidol 21: 38-43.

23. Stefan N, Kantartzis K, Machann J, Schick F, Thamer C, et al. (2008) Identification and characterization of metabolically benign obesity in humans. Arch Intern Med 168: 1609-1616.

24. Durward CM, Hartman TJ, Nickols-Richardson SM (2012) All-cause mortality risk of metabolically healthy obese individuals in NHANES III. J Obes 2012 460321.
25. Fernandez-Bustamante A, Repine JE (2012) The Obesity ARDS Paradox: "A Pre-Conditioning Cloud". J Pulmon Resp Med 2: e122.

26. Muenzer JT, Davis CG, Dunne BS, Unsinger J, Dunne WM, et al. (2006) Pneumonia after cecal ligation and puncture: a clinically relevant "two-hit" model of sepsis. Shock 26: 565-570.

27. Perl M, Hohmann C, Denk S, Kellermann P, Lu D, et al. (2012) Role of activated neutrophils in chest trauma-induced septic acute lung injury. Shock 38: 98-106.

28. Faust-Chan R, Hybertson B, Flores SC, Wright RM, Repine JE (1999) Initiation and tolerance to acute lung injury: yin-yang mechanisms involving interleukin-1. Chest 116: 102S-103S

29. White CW, Ghezzi P, Dinarello CA, Caldwell SA, McMurtry IF, et al. (1987) Recombinant tumor necrosis factor/cachectin and interleukin 1 pretreatment decreases lung oxidized glutathione accumulation, lung injury, and mortality in rats exposed to hyperoxia. J Clin Invest 79: 1868-1873.

30. Brown JM, White CW, Terada LS, Grosso MA, Shanley PF, et al. (1990) Interleukin 1 pretreatment decreases ischemia/reperfusion injury. Proc Nat Acad Sci U S A 87: 5026-5030.

31. Garcia C, Julier K, Bestmann L, Zollinger A, von Segesser LK, et al. (2005) Preconditioning with sevoflurane decreases PECAM-1 expression and improves one-year cardiovascular outcome in coronary artery bypass graft surgery. Br J Anaesth 94: 159-165.

32. Hausenloy DJ, Mwamure PK, Venugopal V, Harris J, Barnard M, et al. (2007) Effect of remote ischaemic preconditioning on myocardial injury in patients undergoing coronary artery bypass graft surgery: a randomised controlled trial. Lancet 370: 575-579.

33. Jackson RM, Frank L (1984) Ozone-induced tolerance to hyperoxia in rats. Am Rev Respir Dis 129: 425-429.

34. Teoh N, Leclercq I, Pena AD, Farrell G (2003) Low-dose TNF-alpha protects against hepatic ischemia-reperfusion injury in mice: implications for preconditioning. Hepatology 37: 118-128.

35. Lecour S, Rochette L, Opie $L$ (2005) Free radicals trigger TNF alpha-induced cardioprotection. Cardiovasc Res 65: 239-243.

36. Lai IR, Chang KJ, Chen CF, Tsai HW (2006) Transient limb ischemia induces remote preconditioning in liver among rats: the protective role of heme oxygenase-1. Transplantation 81: 1311-1317.

37. Kanoria S, Jalan R, Seifalian AM, Williams R, Davidson BR (2007) Protocols and mechanisms for remote ischemic preconditioning: a novel method for reducing ischemia reperfusion injury. Transplantation 84: 445-458

38. Brown JM, Grosso MA, Terada LS, Whitman GJ, Banerjee A, et al. (1989) Endotoxin pretreatment increases endogenous myocardial catalase activity and decreases ischemia-reperfusion injury of isolated rat hearts. Proc Nat Acad Sci U S A 86: 2516-2520.

39. Küntscher MV, Kastell T, Altmann J, Menke H, Gebhard MM, et al. (2002) Acute remote ischemic preconditioning II: the role of nitric oxide. Microsurgery 22 227-231.

40. Xu H, Uysal KT, Becherer JD, Arner P, Hotamisligil GS (2002) Altered tumor necrosis factor-alpha (TNF-alpha) processing in adipocytes and increased expression of transmembrane TNF-alpha in obesity. Diabetes 51:1876-1883.

41. Shakeri-Manesch S, Zeyda M, Huber J, Ludvik B, Prager G, et al. (2009) Diminished upregulation of visceral adipose heme oxygenase-1 correlates with waist-to-hip ratio and insulin resistance. Int J Obes (Lond) 33: 1257-1264.

42. Bao W, Rong S, Zhang M, Yu X, Zhao Y, et al. (2012) Plasma heme oxygenase-1 concentration in relation to impaired glucose regulation in a nondiabetic Chinese population. PLoS One 7: e32223.

43. Glance LG, Wissler R, Mukamel DB, Li Y, Diachun CA, et al. (2010) Perioperative outcomes among patients with the modified metabolic syndrome who are undergoing noncardiac surgery. Anesthesiology 113: 859-872.

44. Lakka HM, Laaksonen DE, Lakka TA, Niskanen LK, Kumpusalo E, et al. (2002) The metabolic syndrome and total and cardiovascular disease mortality in middle-aged men. JAMA 288: 2709-2716

45. Malik S, Wong ND, Franklin SS, Kamath TV, L'Italien GJ, et al. (2004) Impact of the metabolic syndrome on mortality from coronary heart disease, cardiovascular disease, and all causes in United States adults. Circulation 110 1245-1250.

46. Memtsoudis S, Liu SS, Ma Y, Chiu YL, Walz JM, et al. (2011) Perioperative 
pulmonary outcomes in patients with sleep apnea after noncardiac surgery. Anesth Analg 112: 113-121.

47. Shah R, Hinkle CC, Haris L, Shah R, Mehta NN, et al. (2012) Adipose genes down-regulated during experimental endotoxemia are also suppressed in obesity. J Clin Endocrinol Metab 97: E2152-E2159.

48. Langouche L, Marques MB, Ingels C, Gunst J, Derde S, et al. (2011) Critica illness induces alternative activation of M2 macrophages in adipose tissue. Crit Care 15: R245

49. Berg AH, Scherer PE (2005) Adipose tissue, inflammation, and cardiovascular disease. Circ Res 96: 939-949.

50. Hotamisligil GS (2006) Inflammation and metabolic disorders. Nature 444: 860867.

51. Nomiyama T, Perez-Tilve D, Ogawa D, Gizard F, Zhao Y, et al. (2007) Osteopontin mediates obesity-induced adipose tissue macrophage infiltration and insulin resistance in mice. J Clin Invest 117: 2877-2888.

52. Liuzzi A, Savia G, Tagliaferri M, Lucantoni R, Berselli ME, et al. (1999) Serum leptin concentration in moderate and severe obesity: relationship with clinical anthropometric and metabolic factors. Int J Obes Relat Metab Disord 23: 10661073.

53. Lugogo NL, Hollingsworth JW, Howell DL, Que LG, Francisco D, et al (2012) Alveolar macrophages from overweight/obese subjects with asthma demonstrate a proinflammatory phenotype. Am J Respir Crit Care Med 186 404-411.

54. Jain M, Budinger GR, Lo A, Urich D, Rivera SE, et al. (2011) Leptin promotes fibroproliferative acute respiratory distress syndrome by inhibiting peroxisome proliferator-activated receptor- $\hat{\mid}^{3}$. Am J Respir Crit Care Med 183: 1490-1498.

55. Ali Assad N, Sood A (2012) Leptin, adiponectin and pulmonary diseases. Biochimie 94: 2180-2189.

56. Lemos MP, Rhee KY, McKinney JD (2011) Expression of the leptin receptor outside of bone marrow-derived cells regulates tuberculosis control and lung macrophage MHC expression. J Immunol 187: 3776-3784.

57. Mancuso P, Myers MG Jr, Goel D, Serezani CH, O'Brien E, et al. (2012) Ablation of leptin receptor-mediated ERK activation impairs host defense against Gramnegative pneumonia. J Immunol 189: 867-875

58. Vernooy JH, Bracke KR, Drummen NE, Pauwels NS, Zabeau L, et al. (2010) Leptin modulates innate and adaptive immune cell recruitment after cigarette smoke exposure in mice. J Immunol 184: 7169-7177.

59. Mancuso P, Canetti C, Gottschalk A, Tithof PK, Peters-Golden M (2004) Leptin augments alveolar macrophage leukotriene synthesis by increasing phospholipase activity and enhancing group IVC iPLA2 (cPLA2gamma) protein expression. Am J Physiol Lung Cell Mol Physiol 287: L497-502.

60. Koerner A, Kratzsch J, Kiess W (2005) Adipocytokines: leptin--the classical resistin--the controversical, adiponectin--the promising, and more to come. Best Pract Res Clin Endocrinol Metab 19: 525-546.

61. Shore SA, Terry RD, Flynt L, Xu A, Hug C (2006) Adiponectin attenuate allergen-induced airway inflammation and hyperresponsiveness in mice. $J$ Allergy Clin Immunol 118: 389-395.

62. Summer R, Little FF, Ouchi N, Takemura Y, Aprahamian T, et al. (2008) Alveolar macrophage activation and an emphysema-like phenotype in adiponectindeficient mice. Am J Physiol Lung Cell Mol Physiol 294: L1035-1042.

63. Konter JM, Parker JL, Baez E, Li SZ, Ranscht B, et al. (2012) Adiponectin attenuates lipopolysaccharide-induced acute lung injury through suppression of endothelial cell activation. J Immunol 188: 854-863.

64. Seok J, Warren HS, Cuenca AG, Mindrinos MN, Baker HV, et al. (2013) Genomic responses in mouse models poorly mimic human inflammatory diseases. Proc Natl Acad Sci U S A 110: 3507-3512.

65. Mumby S, Upton RL, Chen Y, Stanford SJ, Quinlan GJ, et al. (2004) Lung heme oxygenase- 1 is elevated in acute respiratory distress syndrome. Crit Care Med 32: $1130-1135$.

66. Yin H, Li X, Yuan B, Zhang B, Hu S, et al. (2011) Heme oxygenase-1 ameliorates LPS-induced acute lung injury correlated with downregulation of interleukin-33. Int Immunopharmacol 11: 2112-2117.

67. Soares MP, Bach FH (2009) Heme oxygenase-1: from biology to therapeutic potential. Trends Mol Med 15: 50-58.
68. Sarady-Andrews JK, Liu F, Gallo D, Nakao A, Overhaus M, et al. (2005) Biliverdin administration protects against endotoxin-induced acute lung injury in rats. Am J Physiol Lung Cell Mol Physiol 289: L1131-1137.

69. Kim DH, Burgess AP, Li M, Tsenovoy PL, Addabbo F, et al. (2008) Heme oxygenase-mediated increases in adiponectin decrease fat content and inflammatory cytokines tumor necrosis factor-alpha and interleukin-6 in Zucke rats and reduce adipogenesis in human mesenchymal stem cells. J Pharmaco Exp Ther 325: 833-840.

70. Li M, Kim DH, Tsenovoy PL, Peterson SJ, Rezzani R, et al. (2008) Treatment of obese diabetic mice with a heme oxygenase inducer reduces visceral and subcutaneous adiposity, increases adiponectin levels, and improves insulin sensitivity and glucose tolerance. Diabetes 57: 1526-1535.

71. Hualin C, Wenli X, Dapeng L, Xijing L, Xiuhua P, et al. (2012) The antiinflammatory mechanism of heme oxygenase- 1 induced by hemin in primary rat alveolar macrophages. Inflammation 35: 1087-1093.

72. Drechsler Y, Dolganiuc A, Norkina O, Romics L, Li W, et al. (2006) Heme oxygenase-1 mediates the anti-inflammatory effects of acute alcohol on IL-10 induction involving p38 MAPK activation in monocytes. J Immunol 177: 25922600.

73. Yin H, Li X, Gong Q, Jin X, Gu H, et al. (2010) Heme oxygenase-1 upregulation improves lipopolysaccharide-induced acute lung injury involving suppression of macrophage migration inhibitory factor. Mol Immunol 47: 2443-2449.

74. Freitas A, Alves-Filho JC, Secco DD, Neto AF, Ferreira SH, et al. (2006) Heme oxygenase/carbon monoxide-biliverdin pathway down regulates neutrophi rolling, adhesion and migration in acute inflammation. Br J Pharmacol 149: 345-354.

75. Tzima S, Victoratos P, Kranidioti K, Alexiou M, Kollias G (2009) Myeloid heme oxygenase-1 regulates innate immunity and autoimmunity by modulating IFNbeta production. J Exp Med 206: 1167-1179.

76. von Knethen A, Neb H, Morbitzer V, Schmidt MV, Kuhn AM, et al. (2011) PPAR $\hat{I}^{3}$ stabilizes HO-1 mRNA in monocytes/macrophages which affects IFN- İ $^{2}$ expression. Free Radic Biol Med 51: 396-405.

77. Moller DE (2000) Potential role of TNF-alpha in the pathogenesis of insulin resistance and type 2 diabetes. Trends Endocrinol Metab 11: 212-217.

78. Sobti RC, Kler R, Sharma YP, Talwar KK, Singh N (2012) Risk of obesity and type 2 diabetes with tumor necrosis factor-Î̃ 308G/A gene polymorphism in metabolic syndrome and coronary artery disease subjects. Mol Cell Biochem 360: 1-7.

79. Desvergne B, Wahli W (1999) Peroxisome proliferator-activated receptors: nuclear control of metabolism. Endocr Rev 20: 649-688.

80. Yumuk VD (2006) Targeting components of the stress system as potential therapies for the metabolic syndrome: the peroxisome-proliferator-activated receptors. Ann N Y Acad Sci 1083: 306-318.

81. Odegaard JI, Ricardo-Gonzalez RR, Goforth MH, Morel CR, Subramanian V et al. (2007) Macrophage-specific PPARgamma controls alternative activation and improves insulin resistance. Nature 447: 1116-1120.

82. Xu H, Barnes GT, Yang Q, Tan G, Yang D, et al. (2003) Chronic inflammation in fat plays a crucial role in the development of obesity-related insulin resistance. $\mathrm{J}$ Clin Invest 112: 1821-1830.

83. Xiao B, Xu J, Wang G, Jiang P, Fang F, et al. (2011) Troglitazone-activated PPAR $\hat{I}^{3}$ inhibits LPS-induced lung alveolar type II epithelial cells injuries via TNF-Ît. Mol Biol Rep 38: 5009-5015.

84. Wagner MC, Yeligar SM, Brown LA, Michael Hart C (2012) PPAR $\hat{l}^{3}$ ligands regulate NADPH oxidase, eNOS, and barrier function in the lung following chronic alcohol ingestion. Alcohol Clin Exp Res 36: 197-206.

85. Li WC, Hsiao KY, Chen IC, Chang YC, Wang SH, et al. (2011) Serum leptin is associated with cardiometabolic risk and predicts metabolic syndrome in Taiwanese adults. Cardiovasc Diabetol 10: 36.

86. Loh K, Fukushima A, Zhang X, Galic S, Briggs D, et al. (2011) Elevated hypothalamic TCPTP in obesity contributes to cellular leptin resistance. Cell Metab 14: 684-699.

87. Enriori PJ, Evans AE, Sinnayah P, Cowley MA (2006) Leptin resistance and obesity. Obesity (Silver Spring) 14 Suppl 5: 254S-258S

88. Kim JA, Park HS (2008) White blood cell count and abdominal fat distribution in female obese adolescents. Metabolism 57: 1375-1379. 
89. Herishanu Y, Rogowski O, Polliack A, Marilus R (2006) Leukocytosis in obese individuals: possible link in patients with unexplained persistent neutrophilia. Eur J Haematol 76: 516-520.

90. Kordonowy LL, Burg E, Lenox CC, Gauthier LM, Petty JM, et al. (2012) Obesity is associated with neutrophil dysfunction and attenuation of murine acute lung injury. Am J Respir Cell Mol Biol 47: 120-127.

91. Itoh M, Suganami T, Hachiya R, Ogawa Y (2011) Adipose tissue remodeling as homeostatic inflammation. Int J Inflam 2011: 720926.

92. Weisberg SP, McCann D, Desai M, Rosenbaum M, Leibel RL, et al. (2003) Obesity is associated with macrophage accumulation in adipose tissue. $\mathrm{J}$ Clin Invest 112: 1796-1808.

93. Gordon S, Taylor PR (2005) Monocyte and macrophage heterogeneity. Nat Rev Immunol 5: 953-964.

94. Mosser DM, Edwards JP (2008) Exploring the full spectrum of macrophage activation. Nat Rev Immunol 8: 958-969.

95. Suganami T, Tanimoto-Koyama K, Nishida J, Itoh M, Yuan X, et al. (2007) Role of the Toll-like receptor 4/NF-kappaB pathway in saturated fatty acid-induced inflammatory changes in the interaction between adipocytes and macrophages. Arterioscler Thromb Vasc Biol 27: 84-91.
96. Womack J, Tien PC, Feldman J, Shin JH, Fennie K, et al. (2007) Obesity and immune cell counts in women. Metabolism 56: 998-1004.

97. Nishimura S, Manabe I, Nagasaki M, Eto K, Yamashita H, et al. (2009) CD8+ effector $T$ cells contribute to macrophage recruitment and adipose tissue inflammation in obesity. Nat Med 15: 914-920.

98. van der Weerd K, Dik WA, Schrijver B, Schweitzer DH, Langerak AW, et al (2012) Morbidly obese human subjects have increased peripheral blood CD4 T cells with skewing toward a Treg- and Th2-dominated phenotype. Diabetes 61: 401-408

99. Honiden S, Gong MN (2009) Diabetes, insulin, and development of acute lung injury. Crit Care Med 37: 2455-2464.

100. Moss M, Guidot DM, Steinberg KP, Duhon GF, Treece P, et al. (2000) Diabetic patients have a decreased incidence of acute respiratory distress syndrome. Crit Care Med 28: 2187-2192.

101. Repine JE, Clawson CC, Goetz FC (1980) Bactericidal function of neutrophils from patients with acute bacterial infections and from diabetics. J Infect Dis 142: 869-875. 